\title{
Effect of Remote Ischemic Postconditioning on miRNA-145 and Troponin I levels in STEMI Patients undergoing Primary Percutaneous Coronary Intervention
}

\author{
Pradita Diah Permatasari', Muhammad Fadil², Masyrul Syafri ${ }^{3}$.
}

\footnotetext{
I Resident of Cardiology and Vascular Medicine, Medical Faculty of Andalas University/ RSUP dr. M. Djamil Padang. Email : praditadiahp@gmail.com 2 Cardiology and Vascular Medicine, Medical Faculty of Andalas University/ RSUP dr. M. Djamil Padang. Email : mfadil98@ yahoo.com

3 Cardiology and Vascular Medicine, Medical Faculty of Andalas University/ RSUP dr. M. Djamil Padang.

\author{
Correspondence: \\ Pradita Diah Permatasari, Jl. \\ Shinta Melati, Faculty of Andalas \\ University/ RSUP dr. M. Djamil \\ Padang, C I I Lapai-Padang \\ Sumatera barat 25I43
}

E-mail: praditadiahp@gmail.com
}

\begin{abstract}
Background: Primary Percutaneous Coronary Intervention Procedure $(\mathrm{PPCl})$ results in reperfusion injury which will result in more extensive infarction. Remote Ischemic Postconditioning (RIPC) is a protective strategy to reduce the increase in the area of infarction. miRNA-I45 also plays a role in the protective effect of IPC and RIPC.

Methods: This study uses a pre and post test approach only with control group design with experimental research designs. Data is taken at the Integrated Heart Services Installation RSUP Dr. M. Djamil Padang from July to November 2019, 40 patients with ST-segment elevation myocardial infarction (STEMI) performed RIPC. Bivariate analysis was performed to determine differences in levels of miRNA-I45 and troponin I in STEMI patients underwent PPCI with and without RIPC using the Wilcoxon test and the Mann Whitney test. Results: A total of 40 patients who underwent the $\mathrm{PPCl}$ procedure were divided into two groups PPCI + RIPC $(n=20)$ and PPCI without RIPC $(n=$ 20). There were no significant differences in the basic characteristics between the two groups. There were no significant difference in escalation of median expression of miRNA-I 45 in PPCI+ RIPC [pre test 36.33 (27.44-52.39), post test 34.83 (27.65-65.26), $\mathrm{p}=0.765$ ] compared to PPCl without RIPC [pre test 31.66 (26.3I-43.28), post test 33.43 (26.83-64.97), $p=0.765]$. There were an increase in median troponin I levels in both groups, PPCI+ RIPC [pretest $4,104.70$ (67.30-40,000.00), post test 30,448.50 (I20.00-I6.3192.20), $\mathrm{p}=$ 0.001 ] and PPCl without RIPC [pretest 826.50 (17.00-48.259.00), post test 42.784 .50 (2, I I $9.00-162.897 .00), p=<0.00 I]$.

Conclusion: There were no significant difference in median expression of miRNA-I45 in STEMI patients before and after (48 hours) underwent $\mathrm{PPCl}+\mathrm{RIPC}$ and $\mathrm{PPCl}$ without RIPC. There were a significant difference in median levels of troponin I in STEMI patients before and after (48 hours) underwent PPCI+RIPC and PPCI without RIPC.
\end{abstract}

(Indonesian J Cardiol. 2020;41:01-07)

Keywords: remote ischemic postconditioning, miRNA- I45, troponin I 


\section{Introduction}

A

cute myocardial infarction is one of the leading causes of death in the world and is associated with a poor prognosis. ${ }^{1}$ The incidence of STEMI in Europe ranges from about 43 to 144 cases per 100,000 population per year. While in the United States reported incidents ranged from 50 cases per 100,000 population per year in $2008 .^{2}$ In Indonesia in 2013 according to the Ministry of Health there were around 478,000 patients diagnosed with coronary heart disease with the prevalence of STEMI increasing from $20 \%$ to $40 \%$ of myocardial infarction. ${ }^{3}$ Myocardial infarction occurs due to acute occlusion of the coronary arteries. The main markers of output of myocardial infarction patients are the size of myocardial infarction and left ventricular remodeling. The size of the infarction is related to cardiac troponin levels. Return of blood flow to an organ after a period of absence of flow results in parenchymal damage called ischemic reperfusion injury (IRI). The protective strategy for protecting organs from IRI is remote ischemic postconditioning (RIPC). Postconditioning is done by doing four ischemia limb cycles for 5 minutes (with sphygnomanometer at the pump up to 200 $\mathrm{mmHg}$ ) followed by 5 minutes of reperfusion in the first minute after the first balloon dilatation. . $^{4,5}$

miRNAs also play a role in the protective effects of IPC and RIPC through increased autophagy and axis of the Akt signal. miRNAs can be detected in peripheral circulation and can be found in a stable form. It is estimated that there are about 1000 miRNA in humans, one of which is miRNA- 145 which is a mediator of the process of proliferation and differentiation of vascular smooth muscle cells (VSMCs) and is the most numerous miRNA in healthy artery walls. We chose miRNA-145 as a variable to evaluate because based on research Zhang et al found that decreased levels of miRNA-145 are associated with acute myocardial infarction and are a predictor of risk for heart failure, Yan et al (2018) stated that miRNA-145 inhibits myocardial infarction induced by apoptosis via autophagy associated with the Akt $3 / \mathrm{mTOR}$ pathway. $1,7,8$

The aim of this study was to evaluate the difference in miRNA-145 levels and troponin I levels in STEMI patients undergoing PPCI with RIPC and without RIPC.

\section{Methods}

This research is an experimental study with a research design approach that is pre and post test only with control group design that is to measure the effect of treatment and compare between the experimental and control groups. This research was conducted at the Integrated Heart Services Installation RSUP Dr. M. Djamil Padang from July-November 2019.

Inclusion criteria, namely patients diagnosed with STEMI performed PPCI. Exclusion Criteria were PPCI failure (residual stenosis $>30 \%$ in culprit lesions), TIMI flow $<3$, GFR $<30 \mathrm{ml} / \mathrm{min} / 1.73 \mathrm{~m} 2$, hemodialysis, presence of other cardiac abnormalities (valvulopathy, cardiomyopathy, pericardial disease, congenital heart disease), consumption of glibenclamide (inhibits the effects of ischemic postconditioning), PAD, history of myocardial infarction, cardiomyopathy, pericardial disease, congenital heart disease), consumption of glibenclamide (inhibits the effects of ischemic postconditioning), PAD, history of myocardial infarction, cardiomyopathy, pericardial disease, congenital heart disease cardiogenic, pre and post cardiac arrest.

With a paired analytical formula a large sample of 20 people for each group was obtained. Sampling was done by consecutive sampling. STEMI patients who came from the emergency room for the PPCI procedure were taken blood samples for examination of miRNA-145 and troponin I. The RIPC procedure was performed shortly after cross wiring or cross balloon in the coronary arteries that had a blockage. The patient was given midazolam 1 $\mathrm{mg}$ and fentanyl $25 \mathrm{mcg}$ intravenously as an analgesic. The patient is fitted with a sphygmomanometer cuff on the left upper arm and the cuff is inflated to 200 $\mathrm{mmHg}$ (and $>50 \mathrm{mmHg}$ above systolic blood pressure) for 5 minutes, deflate for 5 minutes for four cycles. Forty-eight hours after PPCI, the patient was taken a blood sample again for examination of troponin I and microRNA-145. Bivariate analysis was performed to determine differences in levels of miRNA-145 and troponin I in STEMI patients underwent PPCI with and without RIPC using the Wilcoxon test and the Mann Whitney test. 


\section{Results}

A total of 40 patients who underwent the PPCI procedure were divided into two groups PPCI + RIPC $(\mathrm{n}=20)$ and PPCI without RIPC $(\mathrm{n}=20)$. Table 4.1 and 4.2 showed the basic characteristic of the patients. There were no significant differences in the basic characteristics between the two groups.

There were no significant difference in escalation of median expression of miRNA-145 in PPCI+ RIPC [pre test 36.33 (27.44-52.39), post test 34.83 (27.65-65.26), $\mathrm{p}=0.765$ ] compared to PPCI without RIPC [pre test 31.66 (26.31-43.28), post test 33.43 (26.83-64.97), p $=0.765]$. miRNA-145 expression is assessed from Cq, where $\mathrm{Cq}$ is defined as the number of PCR cycles when fluorescence meets the threshold of the amplification plot. The smaller the number that appears indicates the fewer PCR cycles needed to reach the threshold, which means more miRNA-145 expressions. Although not statistically significant, $\Delta$ miRNA-145 in subjects conducted by PPCI+RIPC is more negative which means that miRNA-145 expression has increased [PPCI + RIPC group [- 0.46 (-24.74-29.11), PPCI without RIPC group [0.02 (-9.32-33.40), $\mathrm{p}=1,000]$.

There was an increase in median troponin I levels in both groups, PPCI+ RIPC [pretest 4,104.70 (67.3040,000.00), post test 30,448.50 (120.00-16.3192.20), $\mathrm{p}=0.001$ ] and PPCI without RIPC [pretest 826.50 (17.00-48.259.00), post test 42.784 .50 (2,119.00162.897.00), $\mathrm{p}=<0.001]$. There is significant difference in median $\Delta$ Troponin I in the PPCI + RIPC group $[19,736.00(-12,235.0-123,364.20)]$ compared to the PPCI without RIPC group [41,478.35 (1,792.00$163,638.00)], \mathrm{p}=0.007$.

\section{Discussion}

In this study, the median expression of miRNA-145 in subjects before and 48 hours after the PPCI action with RIPC showed $\mathrm{p}$ values that were not statistically significant $(p=0.765)$. Median miRNA-145 expression in subjects before and 48 hours after the PPCI action without RIPC was also obtained p-values that were not statistically significant $(\mathrm{p}=0.765)$. Although statistically it does not have a significant difference value, it can be seen that the expression of miRNA145 in subjects made by PPCI with RIPC has increased compared to subjects not done by RIPC. This result is in line with Liu et al who found that overexpression of miRNA-145 had a protective effect against reperfusion injury in rat myocardium. ${ }^{?}$

Higashi et al conducted a study on rabbits that

Table 4.1 Characteristics of Research Subjects

\begin{tabular}{|c|c|c|c|}
\hline Variable & $\begin{array}{c}\text { RIPC } \\
(n=20)\end{array}$ & $\begin{array}{c}\text { Without RIPC } \\
\quad(n=20)\end{array}$ & p Value \\
\hline Age (year), mean $\pm S D$ & $55,50 \pm 8,03$ & $52,55 \pm 11,00$ & $0,339 \mathrm{a}$ \\
\hline $\operatorname{Sex}(f / \%)$ & & & $0,661^{\mathrm{b}}$ \\
\hline Male & $16(80,0)$ & $18(90,0)$ & \\
\hline Female & $4(20,0)$ & $2(10,0)$ & \\
\hline \multicolumn{4}{|l|}{ Blood pressure, mean $\pm S D$} \\
\hline Systolic & $140,15 \pm 20,72$ & $131,65 \pm 31,29$ & $0,318^{\mathrm{a}}$ \\
\hline Diastolic & $82,00 \pm 13,92$ & $82,40 \pm 20,31$ & $0,943^{\mathrm{a}}$ \\
\hline Body Mass Index (BMI), & $23,56 \pm 2,85$ & $25,18 \pm 3,49$ & $0,117^{\mathrm{a}}$ \\
\hline Hypertension (f/\%) & $12(60,0)$ & $8(40,0)$ & $0,343^{\mathrm{b}}$ \\
\hline Diabetes mellitus (f/\%) & $4(20,0)$ & $3(15,0)$ & $1,000^{\mathrm{b}}$ \\
\hline Smoker $(\mathrm{f} / \%)$ & $15(75,0)$ & $18(90,0)$ & $0,407^{\mathrm{b}}$ \\
\hline Dyslipidemia (f/\%) & $7(35,0)$ & $6(30,0)$ & $1,000^{\mathrm{b}}$ \\
\hline Family history $(\mathrm{f} / \%)$ & $1(5,0)$ & 0 & $\mathrm{n} / \mathrm{a}^{\mathrm{b}}$ \\
\hline Menopause (f/\%) & $4(20,0)$ & $2(10,0)$ & $0,661^{\mathrm{b}}$ \\
\hline Heart rate $(\mathrm{HR})$, mean $\pm \mathrm{SD}$ & $82,45 \pm 18,03$ & $81,95 \pm 19,17$ & 0,933 \\
\hline
\end{tabular}

${ }^{*} \mathrm{p}<0,05$ significant

aindependent sample $T$ test

${ }^{b}$ chi-square 
Table 4.2 Characteristics of Research Subjects based on PPCI Results

\begin{tabular}{|c|c|c|c|}
\hline Variable & $\begin{array}{c}\text { RIPC } \\
(\mathbf{n}=\mathbf{2 0}) \\
\end{array}$ & $\begin{array}{c}\text { Without RIPC } \\
\quad(n=20)\end{array}$ & p Value \\
\hline Ischemic Time (minutes) & $370,85 \pm 198,76$ & $300,40 \pm 144,19$ & $0,207^{a}$ \\
\hline STEMI & & & $\mathrm{n} / \mathrm{a}^{\mathrm{b}}$ \\
\hline STEMI Anterior & $12(60,0)$ & $6(30,0)$ & \\
\hline STEMI Anterior Ekstensif & $3(15,0)$ & $5(25,0)$ & \\
\hline STEMI Inferior & $4(20,0)$ & $3(15,0)$ & \\
\hline STEMI Inferoposterior & $1(5,0)$ & $3(15,0)$ & \\
\hline STEMI Inferior + RV & 0 & $3(15,0)$ & \\
\hline Vessel Disease (VD) & & & $0,132^{b}$ \\
\hline $1 \mathrm{VD}$ & $5(25,0)$ & $9(45,0)$ & \\
\hline $2 \mathrm{VD}$ & $5(25,0)$ & $7(35,0)$ & \\
\hline $3 \mathrm{VD}$ & $10(50,0)$ & $4(20,0)$ & \\
\hline Infarct Related Artery (IRA) (\%) & & & $\mathrm{n} / \mathrm{a}^{\mathrm{b}}$ \\
\hline $\mathrm{LAD}$ & $15(75,0)$ & $12(60,0)$ & \\
\hline LCX & 0 & $1(5,0)$ & \\
\hline RCA & $5(25,0)$ & $7(35,0)$ & \\
\hline Killip & & & $1,000^{b}$ \\
\hline I & $19(95,0)$ & $18(90,0)$ & \\
\hline II & $1(5,0)$ & $2(10,0)$ & \\
\hline
\end{tabular}

${ }^{*} \mathrm{p}<0,05$ significant

aindependent sample $T$ test

${ }^{b}$ chi-square

Table 4.3 Differences in miRNA-145 Expression in STEMI Patients Underwent PPCI with RIPC and without RIPC

\begin{tabular}{|c|c|c|c|c|c|c|}
\hline \multirow[b]{3}{*}{ Variable } & \multicolumn{5}{|c|}{ PPCI } & \multirow[b]{3}{*}{ p Value } \\
\hline & \multicolumn{2}{|c|}{ RIPC } & \multirow[b]{2}{*}{ p value } & \multicolumn{2}{|c|}{ Without RIPC } & \\
\hline & $\begin{array}{c}\text { Pretest } \\
\text { Median } \\
\text { (Min-Maks) }\end{array}$ & $\begin{array}{c}\text { Posttest } \\
\text { (48 hours) } \\
\text { Median } \\
\text { (Min-Maks) } \\
\end{array}$ & & $\begin{array}{c}\text { Pretest } \\
\text { Median } \\
\text { (Min-Maks) }\end{array}$ & $\begin{array}{c}\text { Posttest } \\
\text { (48 hours) } \\
\text { Median } \\
\text { (Min-Maks) } \\
\end{array}$ & \\
\hline miRNA145 & $\begin{array}{c}36,33 \\
(27,44-52,39)\end{array}$ & $\begin{array}{c}34,83 \\
(27,65-65,26)\end{array}$ & 0,765 & $\begin{array}{c}31,66 \\
(26,31-43,28)\end{array}$ & $\begin{array}{c}33,43 \\
(26,83-64,97)\end{array}$ & 0,765 \\
\hline
\end{tabular}

Table 4.4 Difference in $\triangle$ miRNA-145 Expression in STEMI Patients Underwent PPCI with RIPC and without RIPC

\begin{tabular}{|c|c|c|c|}
\hline \multirow[b]{2}{*}{ Variable } & \multicolumn{2}{|c|}{ PPCI } & \multirow[b]{2}{*}{ p Value } \\
\hline & $\begin{array}{c}\text { RIPC } \\
\text { Median (Min-Maks) }\end{array}$ & $\begin{array}{c}\text { Without RIPC } \\
\text { Median (Min-Maks) }\end{array}$ & \\
\hline$\Delta$ miRNA145 & $\begin{array}{c}-0,46 \\
(-24,74-29,11)\end{array}$ & $\begin{array}{c}0,02 \\
(-9,32-33,40)\end{array}$ & 1,000 \\
\hline
\end{tabular}

Table 4.5 Differences in Troponin I Levels in STEMI Patients Underwent PPCI with RIPC and without RIPC

\begin{tabular}{|c|c|c|c|c|c|c|}
\hline \multirow[b]{3}{*}{ Variable } & \multicolumn{5}{|c|}{ PPCI } & \multirow[b]{3}{*}{ p Value } \\
\hline & \multicolumn{2}{|c|}{ RIPC } & \multirow[b]{2}{*}{ p value } & \multicolumn{2}{|c|}{ Without RIPC } & \\
\hline & $\begin{array}{c}\text { Pretest } \\
\text { Median } \\
\text { (Min-Maks) }\end{array}$ & $\begin{array}{c}\text { Posttest } \\
\text { (48 hours) } \\
\text { Median } \\
\text { (Min-Maks) }\end{array}$ & & $\begin{array}{c}\text { Pretest } \\
\text { Median } \\
\text { (Min-Maks) }\end{array}$ & $\begin{array}{c}\text { Posttest } \\
\text { (48 hours) } \\
\text { Median } \\
\text { (Min-Maks) }\end{array}$ & \\
\hline Troponin I & $\begin{array}{c}4.104,70 \\
(67,30- \\
40.000,00)\end{array}$ & $\begin{array}{c}30.448,50 \\
(120,00- \\
16.3192,20)\end{array}$ & $0,001^{*}$ & $\begin{array}{c}826,50 \\
(17,00- \\
48.259,00)\end{array}$ & $\begin{array}{c}42.784,50 \\
(2.119,00- \\
162.897,00)\end{array}$ & $<0,001^{*}$ \\
\hline
\end{tabular}


Indonesian Journal of Cardiology

Table 4.6. Differences in $\triangle$ Troponin I Levels in STEMI Patients Underwent PPCI with RIPC and without RIPC

\begin{tabular}{lcccc}
\hline & \multirow{2}{*}{ Variable } & \multicolumn{2}{c}{ PPCI } & \multirow{2}{*}{ p Value } \\
\cline { 2 - 4 } & & $\begin{array}{c}\text { RIPC } \\
\text { Median (Min-Maks) }\end{array}$ & $\begin{array}{c}\text { Without RIPC } \\
\text { Median (Min-Maks) }\end{array}$ & $0,007^{*}$ \\
\hline \multirow{2}{*}{ Troponin I } & $19.736,00$ & $41.478,35$ & $(1.792,00-163.638,00)$ \\
\hline
\end{tabular}

were made to have coronary occlusion and injected miRNA-145. The results found that the group receiving miRNA-145 had a smaller infarction area and increased left ventricular function. This cardioprotective effect arises from an increase in autofagi and activation of the Akt signal axis, where this effect appears within two days after myocardial infarction and lasts for up to two weeks thereafter. ${ }^{14}$ This is consistent with those conducted by researchers where miRNA-145 expression and infarct area were assessed from Troponin I levels are seen before reperfusion and 48 hours after. ${ }^{10}$ Wei et al stated that patients with coronary artery disease had lower expression of miRNA-126, miRNA-145 and miRNA-155. ${ }^{11}$ According to Rangrez et al there was a significant decrease in expression of miRNA-145 to almost undetectable in atherosclerotic lesions. Fichtlscherer et al. stated a significant decrease in miRNA-145 in the blood of patients with coronary artery disease compared with healthy individuals. miRNA itself is a master gene regulators that can target multiple genes, so miRNA can affect various cellular pathways. Therefore, the selection of therapeutic targets based on miRNA must consider the possibility that one miRNA can play a role in more than one physiological process. ${ }^{12,13,14}$

In this study, the median level of troponin I obtained in subjects before the PPCI with RIPC was $4,104.70$ (67.30-40,000.00) higher than subjects before the PPCI without RIPC was 826.50 (17.00-48.259, 00). This could be due to the greater number of subjects in the RIPC group who experienced anterior STEMI with infarct related artery in LAD which caused a relatively greater infarction area marked by higher troponin I levels. Table 4.5 known troponin I levels in subjects after RIPC action was 30,448.50. Based on the results of statistical tests using the Wilcoxon test obtained $\mathrm{p}$ value $=0.001(\mathrm{p}<0.05)$, meaning that there are significant differences in troponin I levels in STEMI patients who underwent PPCI with RIPC before and after treatment. The median level of troponin I in the PPCI group that was not performed by the RIPC 48 hours after was $42,784.50$. Based on the results of statistical tests using the Wilcoxon test obtained $\mathrm{p}=<0.001(\mathrm{p}$ $<0.05$ ), meaning that there are significant differences in troponin I levels in STEMI patients undergoing PPCI without RIPC before and after treatment. However, if seen from groups conducted by PPCI with RIPC, they experienced an increase in troponin I levels which were lower than those conducted by PPCI alone.

This is in line with research conducted by Bangming Cao et al who assessed CKMB levels at 0.5, 8, 24, 48 and 72 hours after PPCI in groups undergoing PPCI + RIPC and PPCI only. A significant difference was found in the lower CKMB concentration in the PPCI + RIPC group and compared to the PPCI group alone and it was concluded that the infarct area was smaller in the PPCI + RIPC group than the PPCI group alone $(\mathrm{p}=$ 0.02) .7 Thuny et al conducted a study of 50 STEMI patients who underwent PPCI and received RIPC were statistically significant in reducing the area of infarction, levels of creatine kinase and myocardial edema., ${ }^{75}$

Thibault et al. Found an average $47 \%$ reduction in the troponin I under curve area in the postconditioning group compared with the control group and after one year the postconditioning group showed an increase in the left ventricular ejection fraction by $7 \%$ compared to the control group. Research conducted by White et al in 2015 of 197 STEMI patients with TIMI Flow 0 who randomly received RIPostC $4 \times 5$ minutes of inflation / deflation in the upper limb for a moment when PPCI produced a $27 \%$ reduction in infarction area measured by CMR as well as an increase in myocardial salvage index and decreased myocardial edema. Lonborg et al. assessed the effect of postconditioning on 118 patients divided by 1: 1 undergoing PPCI + postconditioning or PPCI alone. Assessed troponin I and cardiac MRI (CMR) peaks and a significant reduction in infarction in the postconditioning group, ST segment elevation resolution, reduction in infarction size by $19 \%$ in three months and reduction in heart failure $(27 \%$ vs $46 \%$; p $=0.048)$. Remote protocol selection in upper or lower 
limb organs in a randomized study showed no significant difference in the results obtained. Research conducted by Zhu et al in 2013 shows that the preconditioning and postconditioning strategies have similar therapeutic potential for cardiac ischemia / reperfusion injury. However, the selection of RIPostC procedures rather than $\mathrm{RIPreC}$ is done because there is often a lack of time for RIPreC procedures. ${ }^{16,17,18,19}$

The CONDI-2 / ERIC-PPCI randomized controlled trial in 2019 conducted at 33 centers in the UK, Denmark, Spain and Serbia stated that remote ischemic conditioning does not improve clinical outcomes (cardiac death or hospitalization for heart failure) at 12 months in patients with STEMI undergoing PPCI. ${ }^{20}$ In CONDI-2/ERIC-PPCI the remote ischemic conditioning procedure was performed before PPCI (RIPreC), while in this study the procedure was carried out shortly after crosswiring (RIPostC). The reason in this study using RIPostC procedure is that the remote ischemic conditioning procedure does not delay the time of PPCI to be performed on patients. This study assessed two variables namely miRNA-145 and troponin I initial and 48 hours after the treatment, while in CONDI-2/ERIC-PPCI clinical outcomes evaluation was conducted 12 months after PPCI. For this reason, this study requires a long-term evaluation to confirm the clinical outcomes of research subjects.

\section{Research Limitations}

The absence of standard miRNA-145 expression in STEMI patients and the function of miRNA as master gene regulators that can target multiple genes is also a limitation of this study, so it is necessary to examine several miRNAs that play a role in myocardial infarction. The location of the anterior STEMI is a confounding variable in this study, so uniformity of the STEMI location is required for future studies. This study took STEMI patients, both total and non totalocclusion. The results of this study should be confirmed by imaging examination with CMR to confirm the calculation of infarct area. It is also necessary to examine other cardioprotective mediators that play a role in RIPC such as Stromal Derived Factor-1 $\alpha$, Adenosine,
Nitrite, Interleukin-10, and Interleukin-1 $\alpha$.

\section{Conclusion}

There was an increase in miRNA-145 expression in PPCI+RIPC group compare to PPCI without RIPC group, but not statistically significant. There was a significant difference in the reduction in infarct area from median levels of troponin I in STEMI patients before and after (48 hours) underwent PPCI+RIPC and PPCI without RIPC. Patients underwent PPCI+RIPC had lower increase of troponin I compare to patients underwent PPCI without RIPC group.

\section{References}

1. Zhang M, Cheng YJ, Sara JD, Liu LJ, Liu LP, Zhao $\mathrm{X}$, et al. Circulating MicroRNA-145 is associated with acute myocardial infarction and heart failure. Chinese medical journal. 2017;130(1):51.

2. Ibanez B, James S, Agewall S, Antunes MJ, Ducci $\mathrm{CB}$, Bueno $\mathrm{H}$, et al. ESC Guidelines for the management of acute myocardial infarction in patients presenting with ST segment elevation. European Heart Journal. 2017:1-66.

3. RISKESDAS. Badan Penelitian dan Pengembangan Kesehatan. Riset Kesehatan Dasar (RISKESDAS). L nas. 2013:1-384.

4. Dong YM, Liu XX, Wei GQ, Da YN, Cha L, Ma CS. Prediction of long-term outcome after acute myocardial infarction using circulating miR-145. Scandinavian journal of clinical and laboratory investigation. 2015;75(1):85-91.

5. Tapuria N, Kumar Y, Habib MM, Amara MA, Seifalian AM, Davidson BR. Remote ischemic preconditioning: a novel protective method from ischemia reperfusion injury-a review. Journal of Surgical Research. 2008;150(2):304-30.

6. Cao B, Wang H, Zhang C, Xia M, Yang X. Remote ischemic Postconditioning (RIPC) of the upper arm results in protection from cardiac ischemiareperfusion injury following primary percutaneous coronary intervention (PCI) for acute ST-segment elevation myocardial infarction (STEMI). Medical science monitor: international medical journal of experimental and clinical research. 2018;24:1017.

7. Kohns M, Huhn R, Bauer I, Brandenburger 
T. miRNA-Mediated Mechanisms of Cardiac Protection in Ischemic and Remote Ischemic Preconditioning-A Qualitative Systematic Review. Shock. 2019;51(1):44-51.

8. Yan L, Guo N, Cao Y, Zeng S, Wang J, Lv F, et al. miRNA 145 inhibits myocardial infarction induced apoptosis through autophagy via Akt $3 / \mathrm{mTOR}$ signaling pathway in vitro and in vivo. International journal of molecular medicine. 2018;42(3):1537-47.

9. Liu Z, Tao B, Fan S, Pu Y, Xia H, Xu L. MicroRNA-145 Protects against Myocardial Ischemia Reperfusion Injury via CaMKII-Mediated Antiapoptotic and Anti-Inflammatory Pathways. Oxidative medicine and cellular longevity. 2019;2019: $1-13$.

10. Higashi K, Yamada Y, Minatoguchi S, Baba S, Iwasa M, Kanamori H, et al. MicroRNA-145 repairs infarcted myocardium by accelerating cardiomyocyte autophagy. American Journal of Physiology-Heart and Circulatory Physiology. 2015;309(11):H1813-26.

11. Wei Y, Jahantigh MZ, Neth P, Weber C, Schober A. MicroRNA-126,-145, and-155: a therapeutic triad in atherosclerosis?. Arteriosclerosis, thrombosis, and vascular biology. 2013;33.3: 449-54.

12. Fichtlscherer S, De Rosa S, Fox H, Schwietz T, Fischer A, Liebetrau C, et al. Circulating microRNAs in patients with coronary artery disease. Circulation research. 2010;107.5: 677-84.

13. Rangrez AY, Massy ZA, Metzinger-Le Meuth V, Metzinger L. miR-143 and miR-145: molecular keys to switch the phenotype of vascular smooth muscle cells. Circulation: Cardiovascular Genetics. 2011;4(2):197-205.

14. Xu M, Mo YY. The AKT-associated microRNAs. Cellular and molecular life sciences. 2012;69.21:3601-12.

15. Thuny F, Lairez O, Roubille F, Mewton N, Rioufol G, Sportouch C, et al. Post-conditioning reduces infarct size and edema in patients with ST-segment elevation myocardial infarction. Journal of the American College of Cardiology.2012;59(24): 217581.

16. Thibault H, Piot C, Staat P, Bontemps L, Sportouch C, Rioufol G, et al. Long-term benefit of postconditioning. Circulation.2008;117(8):1037.

17. White SK, Frohlich GM, Sado DM, Maestrini V, Fontana M, Treibel TA, et al. Remote ischemic conditioning reduces myocardial infarct size and edema in patients with ST-segment elevation myocardial infarction. JACC: Cardiovascular Interventions. 2015;8:178-88.

18. Lavi S, D'Alfonso S, Diamantouros P, Camuglia A, Garg P, Teefy P, et al. Remote ischemic postconditioning during percutaneous coronary interventions: remote ischemic postconditioningpercutaneous coronary intervention randomized trial. Circ Cardiovasc Interv.2014;7(2):225-32.

19. Zhu SB, Liu Y, Zhu Y, Yin GL, Wang RP, Zhang $Y$, et al. Remote preconditioning, perconditioning, and postconditioning: a comparative study of their cardio-protective properties in rat models. Clinics.2013;68(2): 263-8.

20. Hausenloy DJ, Kharbanda RK, Møller UK, Ramlall M, Aarøe J, Butler R, et al. Effect of remote ischaemic conditioning on clinical outcomes in patients with acute myocardial infarction (CONDI-2/ERICPPCI): a single-blind randomised controlled trial. The Lancet.2019;394:1415-24. 